\title{
PARAMETRIC STUDY OF THE EVAPORATION RATE IN THE PRESENCE OF AN AIRFLOW
}

\author{
Abdelouahad Aliouali ${ }^{1}$, Kamel Talbi ${ }^{2}$, Rafik Bouakkaz ${ }^{3 *}$ \\ ${ }^{1}$ Laboratory of Mechanical Engineering: LGM RP BP 145, 07000 Biskra, Algeria \\ ${ }^{2}$ Mechanical Engineering Department University Frères Mentouri Constantine 1 \\ BP 325, 25017 Constantine, Algeria \\ ${ }^{3}$ Military Academy of Cherchell, Tipaza, Algeria
}

Received 13.08.2019

Accepted 01.10.2019

\begin{abstract}
The present work consists of determining the rate of evaporation through a porous and permeable flat wall surface in the presence of a laminar flow of dry air. We propose a numerical analysis of the mass transfer in the gaseous phase whose physical properties are variable. A parametric study of the different influences on the mass flow rate of steam is carried out. The mathematical formulation of this problem is based on the coupled equations of the dynamic field, temperature, and mass fraction of the vapor. The system of equations with the boundary conditions and the interface is solved through the finite volume method.
\end{abstract}

Keywords: evaporation rate; stagnant film model; Stefan flux; numerical study.

\section{Introduction}

Evaporation in the presence of airflow has been a subject of great interest for researchers due to its high applicability in many industrial developments. The applications may include the environment, metallurgy, drying, desalinization, and humidification of the air and dehumidification of various products. In the metallurgical field, quenching is used for cooling the metal, leaving the furnace austenitizing. Cooling is achieved by convective boiling, which is most widely used for its high ability to remove the heat flux at very high temperatures. The temporal and spatial evolution of heat transfer coefficients on the metal surface is determined by the thermo-hydraulic conditions of steam and water. When the liquid temperature is close to the saturation temperature, there is vaporization of the portion of the liquid directly in contact with the wall. The evaporation rate determines the width of the surface of the liquid film, which has the effect of increasing the width of the face of rewet and thus the heat exchange at the

*Corresponding author: Rafik Bouakkaz,r.bouakkaz@gmail.com 
interface level. The determination of the evaporation rate is essential, in this context among the few authors who have proposed models of prediction of the evaporation rates, which may be cited. Brighton [1], considers that the evaporation rate is the integral of the product of the concentration and the velocity in the boundary layer. It introduces into the equation system the roughness and friction velocity of the turbulent boundary layer. Also, Kawamura and Mackay [2], carried out tests on large plies by considering the profile of the wind; they determine a computation correlation of the local evaporation rate at the surface. Braun and Caplan [3], from wind tunnel tests, have determined empirical correlations for different types of liquids evaporating under given pressure and temperature conditions. They obtained a correlation giving the average and overall flow to all liquids according to their physical properties.

We consider in this article the case of evaporation through a flat porous and permeable wall surface (see Figure 1). As an example of an evaporated substance, we chose the liquid water contained in the porous zone. In contact with airflow, evaporation depends on the mass boundary layer, which plays a significant role in mass transfer. The fluid in the vicinity of the wall is braked because of the non-slip condition. The stagnant and static film is the thickness $\delta_{c}$ in the mass boundary layer (see Figure 2). Recently, John $H$ et al. [4], present an analysis based on the model of the stagnant film, which makes it possible to express the flux of total surface mass of vapor at the interface $\dot{\mathrm{m}}_{\mathrm{v}}^{\mathrm{s}}=$ $\left(\rho_{\mathrm{v}} \mathrm{v}_{\mathrm{s}}+\mathrm{j}_{\mathrm{v}, \mathrm{S}}\right)$. The compensatory or counter-diffusion flow of the air towards the evaporation surface causes a flow of the air-vapor mixture of normal velocity to the wall $v_{\mathrm{s}}=-\frac{\mathrm{D}_{\mathrm{pv}}}{\rho_{\mathrm{a}}} \frac{\mathrm{R}_{\mathrm{v}}}{\mathrm{R}_{\mathrm{a}}} \frac{\partial \mathrm{p}_{\mathrm{v}}}{\partial \mathrm{y}}$. This vertical movement causes an additional convective mass flow of steam called Stefan flux $\left(\rho_{\mathrm{v}} \mathrm{v}_{\mathrm{s}}\right)$. When the compensatory movement is weak, this flow is negligible. In the latter case, the mass transfer of steam is reduced to the mass diffusion flux $\mathrm{j}_{\mathrm{v}, \mathrm{s}}^{\mathrm{s}} \cong-\mathrm{D}_{\mathrm{pv}} \frac{\partial \mathrm{p}_{\mathrm{v}}}{\partial \mathrm{y}}$, analogous to the heat flux transferred by convection.

With: $\mathrm{R}_{\mathrm{a}}=\mathrm{R} / \mathrm{M}_{\mathrm{a}}, \mathrm{R}_{\mathrm{v}}=\mathrm{R} / \mathrm{M}_{\mathrm{v}}, \mathrm{D}_{\mathrm{pv}}=\mathrm{D}_{\mathrm{v}-\mathrm{a}} /\left(\mathrm{R}_{\mathrm{v}} \mathrm{T}\right)$

The objective of the present work is the numerical analysis of the mass transfer phenomenon in the gas phase during evaporation through a flat porous and permeable wall surface. We propose a parametric study of the influence of the temperature, the pressure, and the velocity of the flow on the vapor mass flow is carried out, as well as the influence of time. 


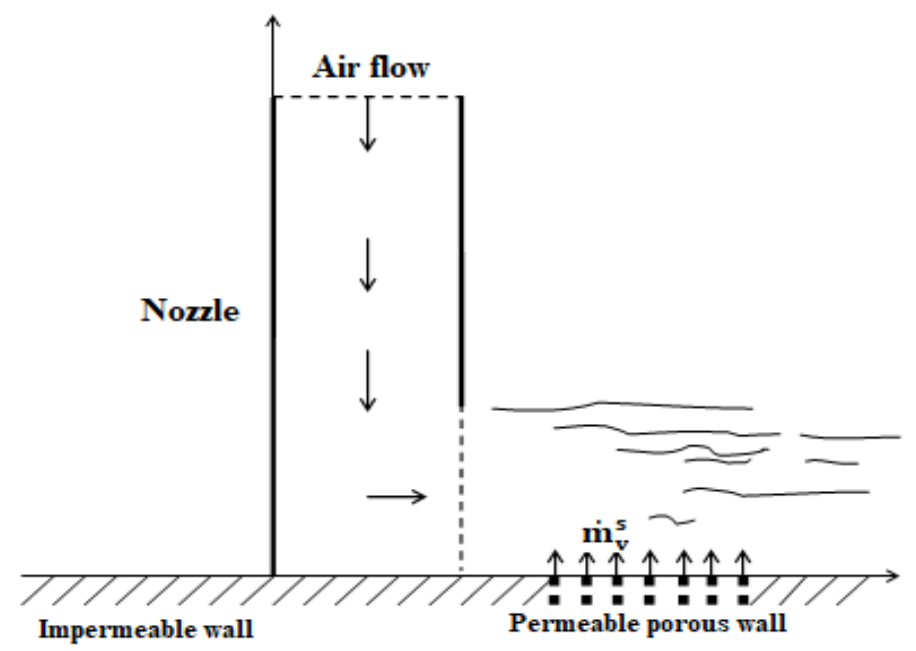

Fig. 1. Evaporation in the presence of airflow.

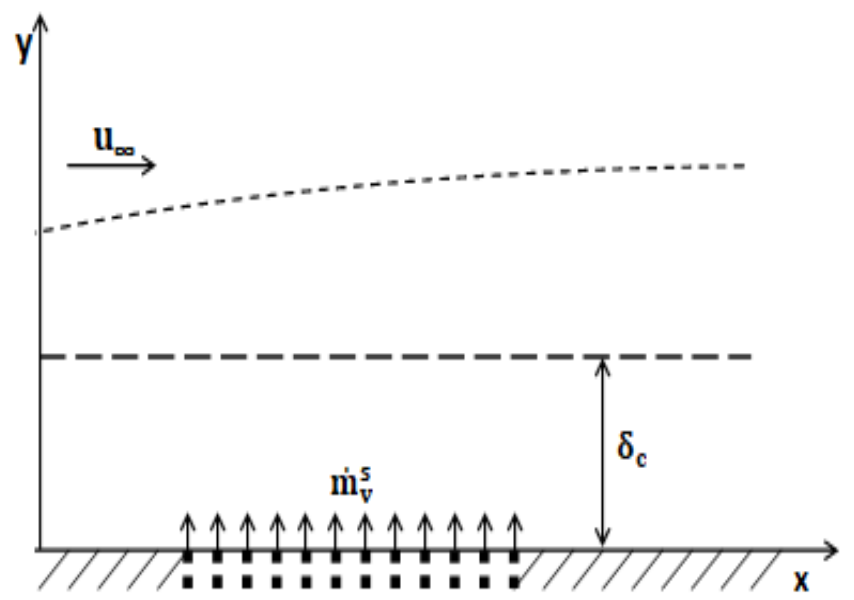

Fig. 2. Stagnant film in the boundary layer of mass.

\section{Mathematical formulation}

Consider that there is vaporization of liquid water at the surface in the permeable zone where the wall is porous. The energy required for this vaporization is assumed to come from an internal heat source in this area. The partial pressure of the resulting water vapor at the wall is equal to the saturation vapor pressure at the wall temperature $\mathrm{T}_{\mathrm{S}}$. The rectangular nozzle introduces dry air at a temperature $\mathrm{T}_{0}$, perpendicular to the surface of the horizontal plane. By impact, the flow of jet air is deflected by the lateral opening of the nozzle and flows laterally. It causes shifting the steam over the permeable zone and maintains the thermodynamic imbalance responsible for the dynamics of evaporation and heat exchange at the air-wall interface. The following hypotheses are considered for our 
system of equations: the flows are two-dimensional and laminar. The evaporation surface is permeable only to steam. The moist air consisting of dry air and water vapor is considered a perfect gas. The physical properties of moist air are variable. The following are considered negligible: the compression energy, the viscous dissipation, the radiation, and the thermodiffusion terms related to the effects of Duffour and Soret.

The index (o) indicates the reference values defined at the inlet of the nozzle; the dimensionless variables are as follows:

$$
\begin{gathered}
x=\frac{x}{X_{0}} y^{*}=\frac{y}{X_{0}} u=\frac{u}{V_{0}} v^{\cdot}=\frac{v}{V_{0}} p=\frac{P-P_{y}(y)}{\rho_{0} V_{\max 0}^{2}} T^{\cdot}=\frac{T-T_{0}}{T_{s}-T_{0}} \rho \cdot=\frac{\rho}{\rho_{0}} C_{p}=\frac{C_{p}}{C_{0}} \mu= \\
\frac{\mu}{\mu_{0}} \lambda=\frac{\lambda}{\lambda_{0}} D_{v-a^{\prime}}=\frac{D_{v-a}}{D_{v-a_{0}}} t^{\cdot}=\frac{t}{t_{0}} t_{0}=\frac{X_{0}}{V_{\max 0}}
\end{gathered}
$$
equation:

$\mathrm{P}_{\mathrm{y}}(\mathrm{y})$ : is the thermodynamic pressure on the domain boundary DE, given by the

$$
P_{y}(y)=P_{0}-\int_{0}^{y}(\rho g) d y
$$

The transfer equations then take the following dimensionless forms:

\section{Governing equations}

- Continuity equation

$$
\frac{\partial\left(\rho^{\prime}\right)}{\partial t^{\prime}}+\frac{\partial\left(\rho^{\prime} u^{\prime}\right)}{\partial x^{\prime}}+\frac{\partial\left(\rho^{\prime} v^{\prime}\right)}{\partial y^{\prime}}=0
$$

- Motion equation

X-direction:

$$
\frac{\partial\left(\rho^{\prime} u^{\prime}\right)}{\partial t^{\prime}}+\frac{\partial}{\partial x^{\prime}}\left(\rho^{\prime} u^{\prime} u^{\prime}\right)+\frac{\partial}{\partial y^{\prime}}\left(\rho^{\prime} u^{\prime} v^{\prime}\right)=-\frac{\partial p}{\partial x}+\frac{1}{R e}\left\{\frac { \partial } { \partial x ^ { \prime } } \left[2 \mu^{\prime} \frac{\partial u^{\prime}}{\partial x^{\prime}}-\right.\right.
$$

$\left.\left.\frac{2}{3} \mu^{\prime}\left(\frac{\partial u^{\prime}}{\partial x^{\prime}}+\frac{\partial v^{\prime}}{\partial y^{\prime}}\right)\right]+\frac{\partial}{\partial y^{\prime}}\left[\mu^{\prime}\left(\frac{\partial u^{\prime}}{\partial y^{\prime}}+\frac{\partial v^{\prime}}{\partial x^{\prime}}\right)\right]\right\}$

y-direction:

$$
\begin{gathered}
\frac{\partial}{\partial t^{\prime}}\left(\rho^{\prime} v^{\prime}\right)+\frac{\partial}{\partial x^{\prime}}\left(\rho^{\prime} v^{\prime} u^{\prime}\right)+\frac{\partial}{\partial x^{\prime}}\left(\rho^{\prime} v^{\prime} v^{\prime}\right)=-\left[\frac{\partial p^{\prime}}{\partial y^{\prime}}\right]+\frac{1}{R e}\left\{\frac{\partial}{\partial x^{\prime}}\left[\mu^{\prime}\left(\frac{\partial u^{\prime}}{\partial y^{\prime}}+\frac{\partial v^{\prime}}{\partial x^{\prime}}\right)\right]+\right. \\
\left.\frac{\partial}{\partial y^{\prime}}\left[2 \mu^{\prime} \frac{\partial v^{\prime}}{\partial y^{\prime}}-\frac{2}{3} \mu^{\prime}\left(\frac{\partial u^{\prime}}{\partial y^{\prime}}+\frac{\partial v^{\prime}}{\partial x}\right)\right]\right\}+\frac{1}{F r}\left(1-\rho_{y^{\prime}}(y)\right.
\end{gathered}
$$

- Energy equation:

$$
\begin{aligned}
& \frac{\partial}{\partial t^{\prime}}\left(\rho^{\prime} c_{p}{ }^{\prime} T^{\prime}\right)+\frac{\partial}{\partial x^{\prime}}\left(\rho^{\prime} c_{p}{ }^{\prime} u^{\prime} T^{\prime}\right)+\frac{\partial}{\partial y^{\prime}}\left(\rho^{\prime} c_{p}{ }^{\prime} v^{\prime} T^{\prime}\right)=\frac{1}{\operatorname{Pr} \operatorname{Re}}\left[\frac{\partial}{\partial x^{\prime}}\left(-k^{\prime} \frac{\partial T^{\prime}}{\partial x^{\prime}}\right)+\right. \\
& \left.\frac{\partial}{\partial y^{\prime}}\left(-k^{\prime} \frac{\partial T^{\prime}}{\partial y^{\prime}}\right)\right]
\end{aligned}
$$


- Mass equation

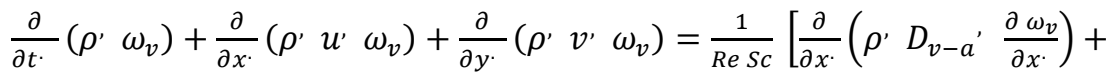

$$
\begin{aligned}
& \left.\frac{\partial}{\partial y^{\cdot}}\left(\rho^{\prime} D_{v-a^{\prime}} \frac{\partial \omega_{v}}{\partial y^{\prime}}\right)\right]
\end{aligned}
$$

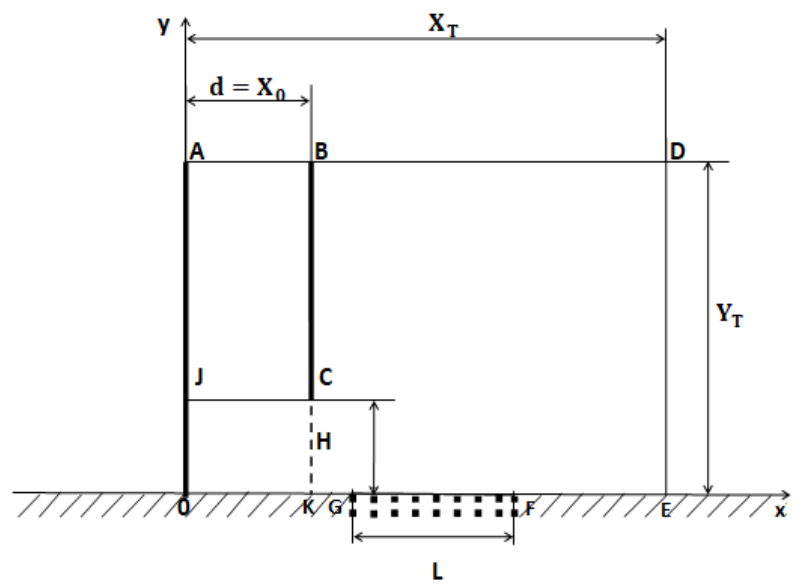

Fig. 3. Representation of numerical calculation domain.

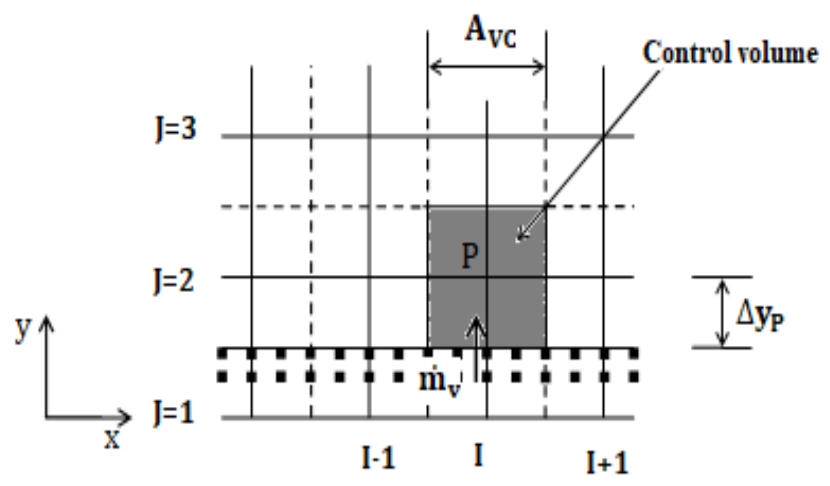

Fig. 4. Part of the mesh control volume (cell adjacent to the wall).

\section{Boundary and interface conditions}

The velocity distribution at the inlet of the nozzle is parabolic.

- Nozzle inlet AB:

$$
u^{\prime}=0, v^{\prime}=-4\left(x^{\prime}-x^{\prime 2}\right), T^{\prime}=0, \omega_{v}=0 .
$$

We assume that the $\mathrm{BC}$ wall of the nozzle is made of a good heat-conducting material of negligible thickness. The temperature of the wall is the same as the local temperature of the gas. 
- Wall of the nozzle BC:

$$
u^{\prime}=0, v^{\prime}=0, T^{\prime}=T_{g a z}^{\prime},\left(\partial \omega_{v} / \partial x^{\prime}\right)=0,
$$

- Exit of the domain BD:

$$
u^{\prime}=0,\left(\partial v^{\prime} / \partial y^{\prime}\right)=0, T^{\prime}=0, p^{\prime}=0, \omega_{v}=0 .
$$

- Exit of the domain DE:

$$
v^{\prime}=0, p^{\prime}=0, T^{\prime}=0,\left(\partial \omega_{v} / \partial x^{\prime}\right)=0,
$$

- Wall OA:

$$
u^{\prime}=0, v^{\prime}=0,\left(\partial T^{\prime} / \partial x^{\prime}\right)=0,\left(\partial \omega_{v} / \partial x^{\prime}\right)=0,
$$

- Air-Wall interface:

Impermeable zone $\mathrm{EF}$ and $\mathrm{GO}$ :

$$
u^{\prime}=0, v^{\prime}=0, T^{\prime}=0, \omega_{v}=0,
$$

Permeable zone GF:

$$
u^{\prime}=0, v^{\prime}=v_{s}{ }^{\prime}, T^{\prime}=T_{s}^{\prime},
$$

The dimensionless length of the permeable zone is: $\left(\mathrm{L} / \mathrm{X}_{0}\right)=5$

The dimensionless density mass on the DE boundary of the domain is: $\rho_{\mathrm{y}}(\mathrm{y})=1$ The following equation gives the term local source of mass, in the dimensionless form:

$$
\left(\dot{m}_{v}\right)^{\prime}=\frac{D_{P}}{R_{v}} \frac{p}{T_{P}} \frac{A_{c e l l}}{\Delta y_{P}} \ln \left[\frac{p-p_{v P}}{p-P_{S a t}\left(T_{S}\right)}\right]\left(\frac{1}{\rho_{0} V_{\max 0}^{2} X_{0}}\right)
$$

where $A_{\text {cell }}$ is the area of the cross-sectional area of the control volume adjacent to the wall surrounding node $\mathrm{P}$ (see figure 4 ). At the node $\mathrm{P}$ are considered, $\mathrm{D}_{\mathrm{P}}$ the diffusivity of the vapor in the air, $\mathrm{p}$ and $\mathrm{p}_{\mathrm{vP}}$ respectively the pressure of the humid and partial air of the steam. $\mathrm{P}_{S a t}\left(\mathrm{~T}_{\mathrm{S}}\right)$ is the saturation vapor pressure at the temperature $\mathrm{T}_{\mathrm{S}}$ at the wall and the constant $R_{v}=R / M_{v}$.

The term local source of heat, whose expression is similar to that given in [5], is written in dimensionless form as follows:

$$
\left(q_{S}\right)^{\prime}=-\frac{\mu}{P r} \frac{C_{P}\left(T_{P}-T_{S}\right)}{\Delta y_{P}} A_{\text {cell }}\left(\frac{\mu_{0}}{X_{0} \rho_{0} V_{\max 0}}\right)
$$

Where $T_{P}$ and $T_{S}$ are respectively, the temperature at the node $\mathrm{P}$ and the wall. Except for the density mass that can be obtained by the perfect gas state equation, the physical properties of moist air are determined by empirical or experimental correlation formulas [6-12]. 


\section{Numerical details}

The numerical resolution of the coupled conservation equations governing the evaporation phenomenon is ensured by the finite volume method using the SIMPLER algorithm proposed by Patankar [13]. The domain of calculation is determined by the rectangular section noted $\left(\mathrm{X}_{\mathrm{T}} \mathrm{xY}_{\mathrm{T}}\right)$. We have predicted the calculation stop test by checking the precision criterion, which for our system of equations is the residual on the continuity equation whose value does not exceed $10^{-4}$. In order to optimize the precision of the results, the pitch of the mesh is variable according to the zones considered of the domain of computation. Figure 5 shows the diagram of the mesh; we adopt a progressive variation both in the $\mathrm{Ox}$ direction and in the $\mathrm{Oy}$. On $\mathrm{Ox}$, the pitch is constant up to the nozzle wall; it then increases according to a progression geometric. On $\mathrm{Oy}$, from the impact surface to the exit of the nozzle, the pitch increases with a geometric progression and then with a different reason until the entry of the nozzle, while avoiding a sudden change. The mesh test is carried out, the results are grouped in Table 1, and we notice that for the dynamics, according to the values of the criteria selected are very close. So, we chose the $91 \times 91$ mesh for the $21 \times 21$ domain size.

Table1. Dynamic criteria values for different sizes of the computing domain and different mesh.

\begin{tabular}{cccccc}
\hline $\begin{array}{c}\text { Size of the } \\
\text { domain of }\end{array}$ & Mesh & $\mathrm{U}_{\max } / \mathrm{V}_{\max 0}$ & \multicolumn{2}{c}{$\mathrm{U}_{\max }$} & \multirow{2}{*}{$\Psi_{\max }$} \\
\cline { 4 - 5 } calculation & & & $\mathrm{x} / \mathrm{X}_{0}$ & $\mathrm{y} / \mathrm{X}_{0}$ & \\
\hline $41 \mathrm{X}_{0} \times 41 \mathrm{X}_{0}$ & $91 \times 91$ & 0.5462 & 1.0000 & 0.9651 & 0.8394 \\
$31 \mathrm{X}_{0} \times 31 \mathrm{X}_{0}$ & $91 \times 91$ & 0.5473 & 1.0000 & 0.9651 & 0.8394 \\
$21 \mathrm{X}_{0} \times 21 \mathrm{X}_{0}$ & $91 \times 91$ & 0.5480 & 1.0000 & 0.9651 & 0.8394 \\
$21 \mathrm{X}_{0} \times 21 \mathrm{X}_{0}$ & $96 \times 96$ & 0.5482 & 1.0000 & 0.9651 & 0.8394 \\
$21 \mathrm{X}_{0} \times 21 \mathrm{X}_{0}$ & $101 \times 101$ & 0.5483 & 1.0000 & 0.9651 & 0.8394 \\
\hline
\end{tabular}

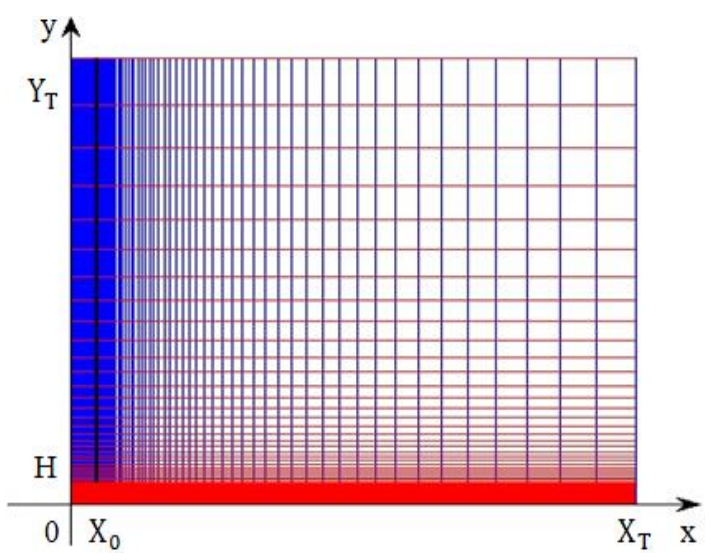

Fig. 5. Representation of the size of the mesh. 


\section{Results and discussion}

We set the state of reference: table 2, parameters with the dimension to promote the physical interpretation of the phenomena that occur during evaporation.

Table 2. Reference state of dimensioned and dimensionless parameters used for calculations.

\begin{tabular}{cccccccccc}
\hline $\begin{array}{c}\mathrm{P}_{0} \\
{[\mathrm{~atm}]}\end{array}$ & $\begin{array}{c}\mathrm{T}_{0} \\
{[\mathrm{~K}]}\end{array}$ & $\begin{array}{c}\mathrm{T}_{\mathrm{s}} \\
{[\mathrm{K}]}\end{array}$ & $\begin{array}{c}\mathrm{U}_{\max } \\
{[\mathrm{m} / \mathrm{s}]}\end{array}$ & $\begin{array}{c}\mathrm{X}_{0} \\
{[\mathrm{~m}]}\end{array}$ & $\begin{array}{c}\mathrm{H} \\
{[\mathrm{m}]}\end{array}$ & $\mathrm{Re}$ & $\mathrm{Fr}$ & $\mathrm{Pr}$ & $\mathrm{Sc}$ \\
\hline 1.0 & 293.15 & 323.15 & 0.756 & 0.01 & 0.01 & 500 & 5.8268 & 0.7165 & 0.6993 \\
\hline
\end{tabular}

The objective of the study is to show the evolution of evaporation by varying the parameters around the reference state defined in Table 2. These are: the evaporation temperature $\mathrm{T}_{\mathrm{s}}$, the thermodynamic total pressure $\mathrm{P}_{0}$, the velocity of the flow as well as the evolution of the evaporation rate according to the time. Two different approaches are possible depending on the scale of the study. In the case where the study is carried out as a function of the distance $\mathrm{x}_{\mathrm{L}}$ between the point considered and the leading edge encountered by the flow, the study is from a local point of view. In the case where the evaporation surface is considered as a uniform and homogeneous entity, the study is from a total point of view; the considered value is the average.

\section{Evaporation temperature}

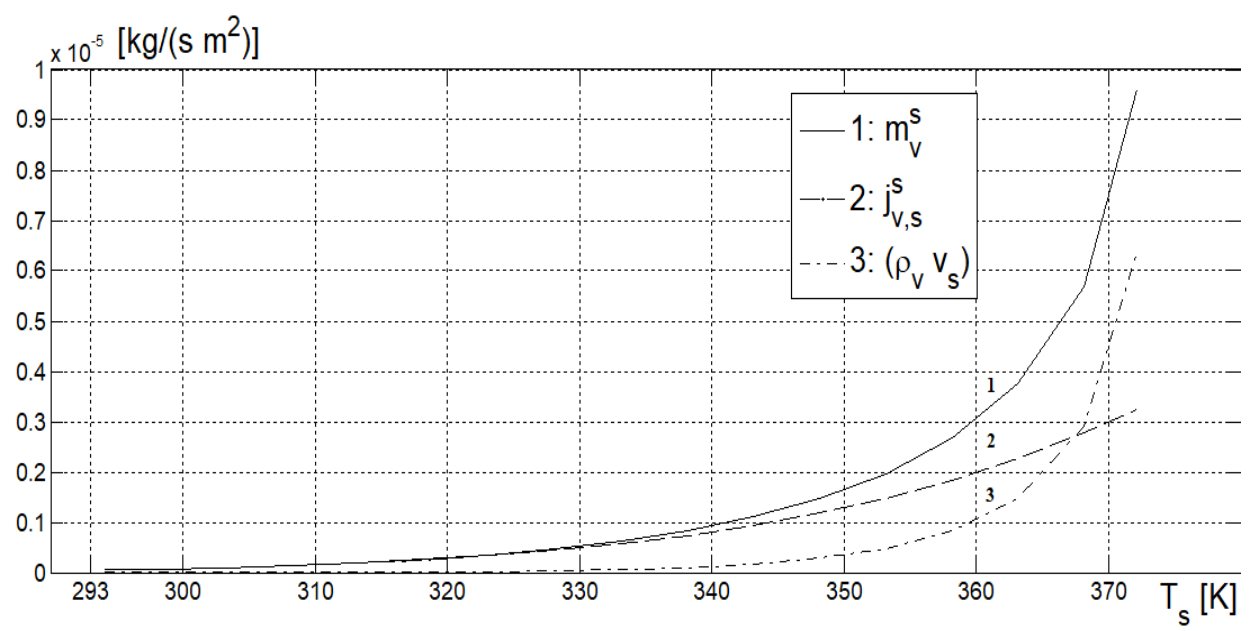

Fig. 6. Influence of the temperature $T_{s}$ on the evaporation rate.

In Figure 6, the curve 1 represents the evolution according to the evaporation temperature $T_{s}$, of the flow rate of the vapor mass $\dot{\mathrm{m}}_{\mathrm{v}}^{\mathrm{s}}=\left(\rho_{\mathrm{v}} \mathrm{v}_{\mathrm{s}}+\mathrm{j}_{\mathrm{v}, \mathrm{s}}\right)$. We find that the average flow increases only very slowly at temperatures between 293 and 330 K. From the limit value $\mathrm{T}_{\mathrm{s}}=330[\mathrm{~K}], \dot{\mathrm{m}}_{\mathrm{v}}^{\mathrm{s}}$ increases very quickly, and this comes from the influence of the compensatory movement, which is no longer weak. Indeed this 
movement generates the convective flow $\left(\rho_{\mathrm{v}} \mathrm{v}_{\mathrm{s}}\right)$, represented by curve 3 which reaches very important values and consequently the flow $\dot{\mathrm{m}}_{\mathrm{v}}^{\mathrm{s}}$, increases rapidly concerning the diffusion rate $\mathrm{j}_{\mathrm{v}, \mathrm{s}}^{\mathrm{s}}$, indicated by curve 2 . This temperature limit $\mathrm{T}_{\mathrm{s}}=330 \mathrm{~K}$ corresponding to $50{ }^{\circ} \mathrm{C}$, is in perfect agreement with that found in the literature of which we can cite the references [4, 14, 15]. It delimits two types of evaporation rate. The low rate of evaporation in the case where the temperature $\mathrm{T}_{\mathrm{S}}$ is less than $330 \mathrm{~K}$ - we can consider the analogy between the convection transfer of heat and mass by the approximation $\dot{\mathrm{m}}_{\mathrm{v}}^{\mathrm{s}} \cong$ $\mathrm{j}_{\mathrm{v}, \mathrm{s}}^{\mathrm{s}}$. The high rate of evaporation is when the temperature $\mathrm{T}_{\mathrm{s}}$ approaches the boiling temperature, the flow $\left(\rho_{\mathrm{v}} \mathrm{v}_{\mathrm{S}}\right)$, is no longer negligible, and the analogy can no longer be considered.

\section{Total thermodynamic pressure}

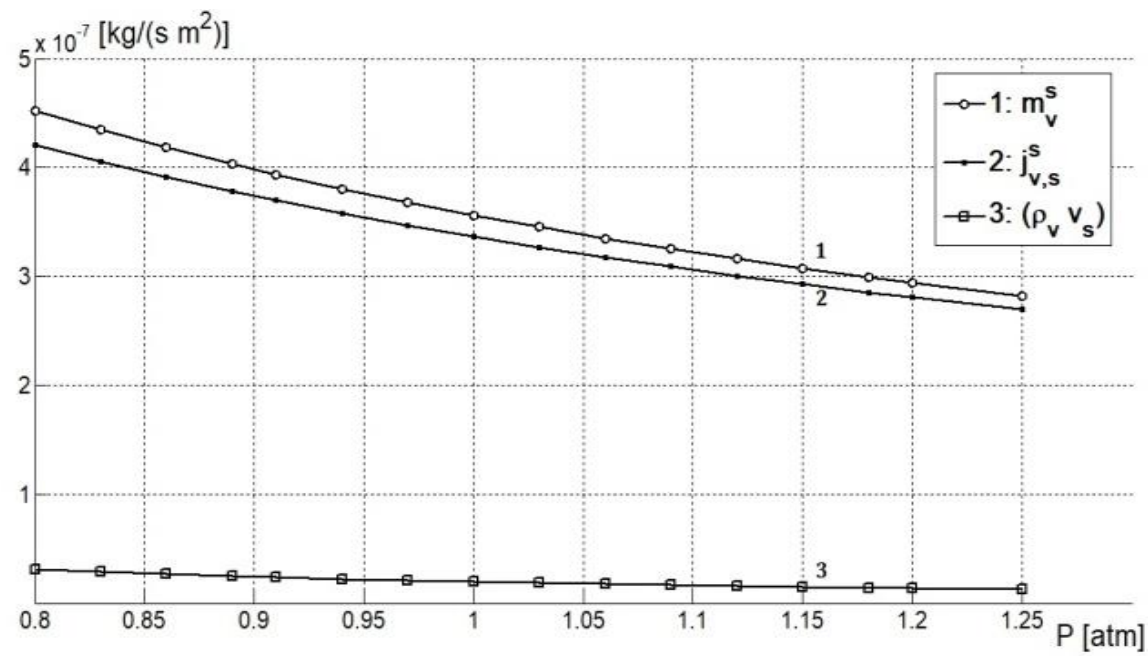

Fig. 7. Evolution of the evaporation rate according to the pressure $P_{0}$.

Figure 7 shows a decrease in the evaporation rate $\dot{\mathrm{m}}_{\mathrm{v}}^{\mathrm{s}}$, when the pressure $\mathrm{P}_{0}$ increases. Indeed, the increase of the total pressure causes, on the one hand, the decrease of the diffusion coefficient and the flux $\mathrm{j}_{\mathrm{v}, \mathrm{s}}^{\mathrm{s}}$, represented by curve 2 on the other hand, slows Stefan's counter-diffusion flow $\left(\rho_{\mathrm{v}} \mathrm{v}_{\mathrm{S}}\right)$, as points it out the curve 3 , which is a convective type mass transfer.

\section{Flow velocity}

The flow of air over the permeable wall causes on its surface the displacement of the vapor resulting from the vaporization. This phenomenon maintains the thermodynamic imbalance at the interface of the latter. We note in Figure 8 that the average mass fraction $\omega_{v-m}$, decreases monotonically with velocity $U_{m a x}$, this is due to the increased entrainment of steam by the airflow as the velocity increases. Figure 9 represents the evolution of the local mass fraction $\omega_{\mathrm{v}-\mathrm{L}}$ for different velocities $U_{\text {max }}$. On curves 1-4; we find the decrease of $\omega_{v-L}$, with the increase $U_{\max }$ of the sweep velocity of the vapor above the evaporation surface. On the other hand, we also notice that the local mass fraction $\omega_{\mathrm{v}-\mathrm{L}}$ increases, because of the accumulation of the increasing vapor with 
the distance. However, around the downstream end of the flow, the mass fraction decreases due to the diffusion of the surrounding drier outside air into this zone.

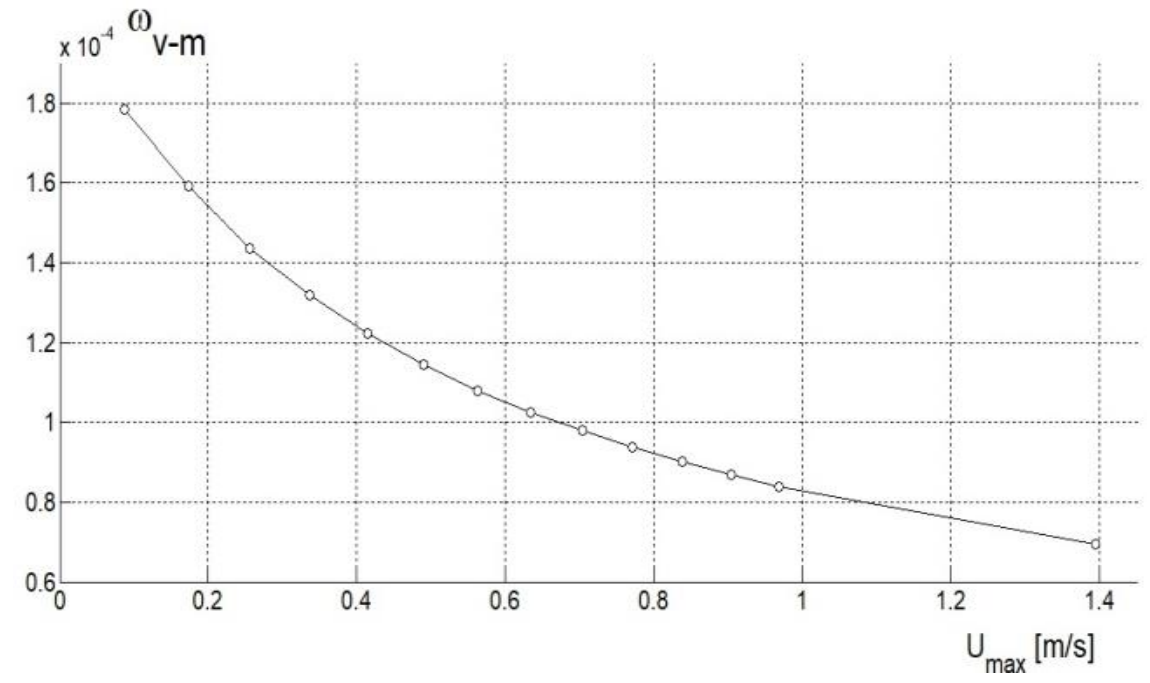

Fig. 8. Average mass fraction $\omega_{v-m}$ according to the velocity $U_{\max }$.

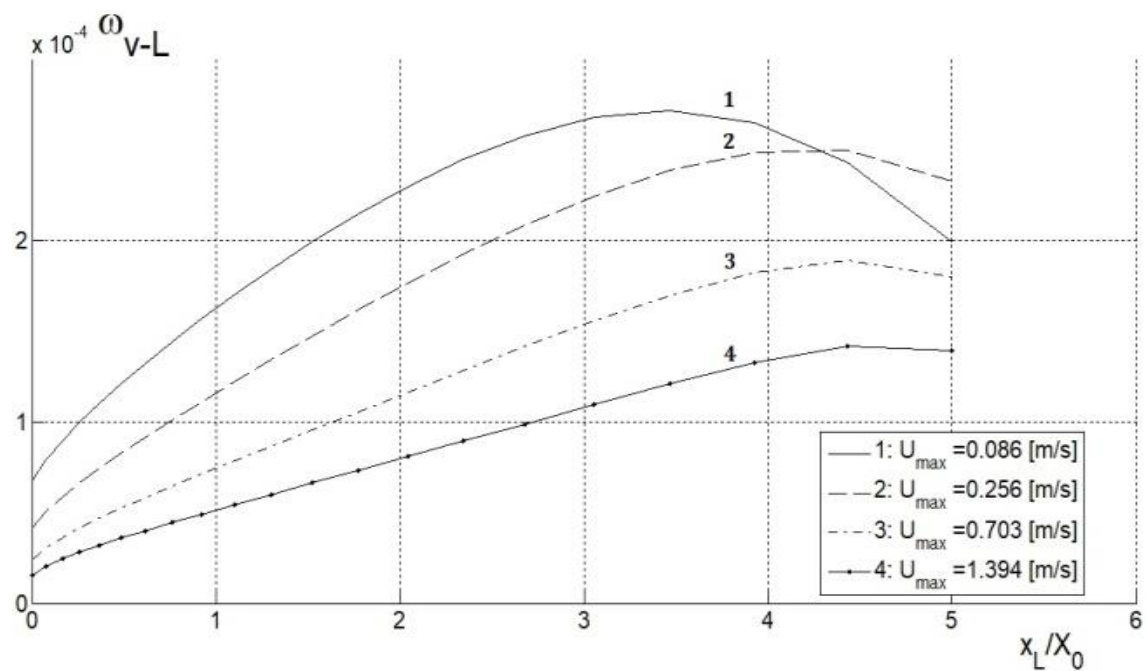

Fig. 9. Local mass fraction $\omega_{v-L}$ depending on the distance $x_{L} / X_{0}$ and for different speeds.

Figure 10, represents the evolution of the average surface flow rate $m_{v-m}^{s}$ as a function of the velocity $U_{\max }$. Figure 8 shows the decrease of the fraction $\omega_{v-m}$ mass average with the velocity $U_{\max }$. As fraction mass of the steam is linked with partial pressure, this one diminishes also. This implicates the increase of difference between the pressure of saturation of the steam and the partial pressure of the vapor in the air. Therefore the rate $\mathrm{m}_{\mathrm{v}-\mathrm{m}}^{\mathrm{s}}$ increases with $\mathrm{U}_{\mathrm{max}}$. Conversely, the growth of the local mass 
fraction $\omega_{v-L}$ with the distance $x_{L}$, that decreases at the same time the rate of local evaporation $\mathrm{m}_{\mathrm{v}-\mathrm{L}}^{\mathrm{s}}$ as shown in Figure 11. Downstream of the flow, there is also an increase in the evaporation rate due to the reduction of the mass fraction in this zone, Figure 9.

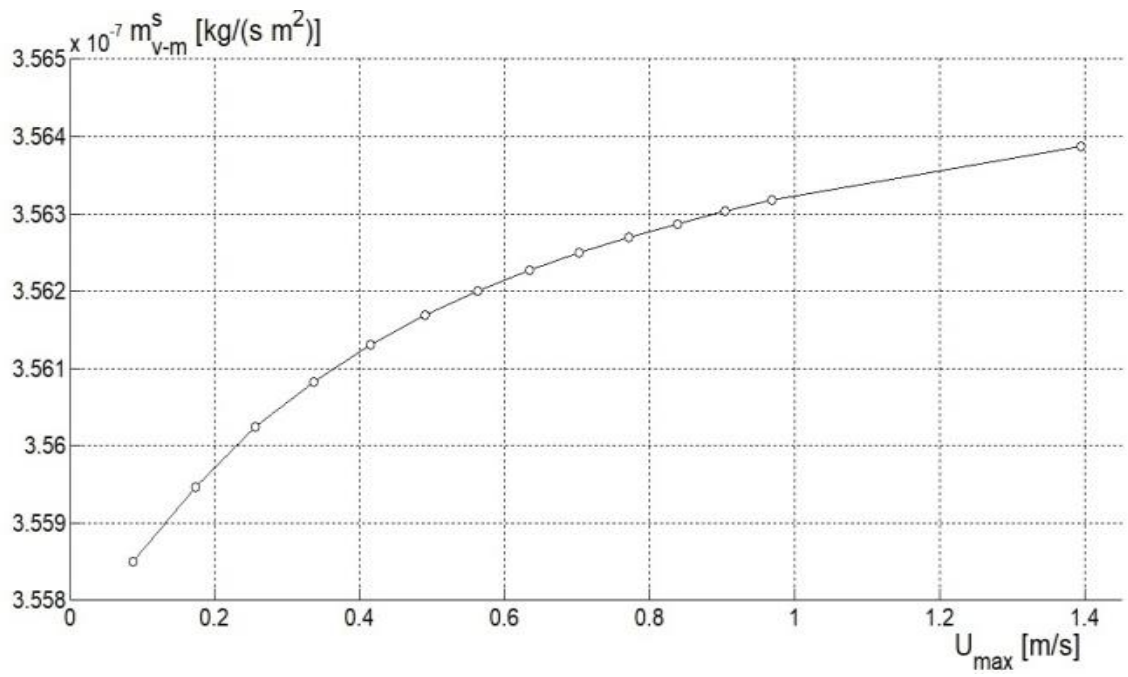

Fig. 10. Average evaporation rates $m_{v-m}^{s}$ as a function of velocity $U_{\max }$.

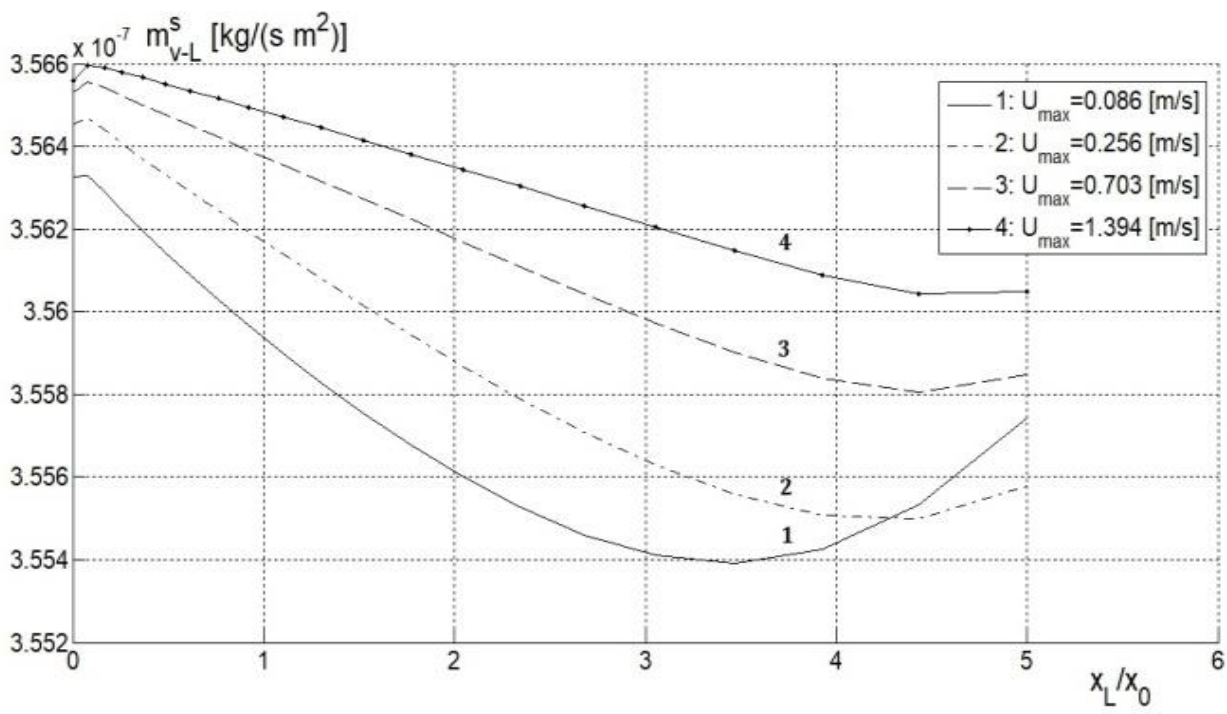

Fig. 11. Local evaporation rates $m_{v-L}^{S}$ according to the distance $\left(x_{L} / X_{0}\right)$ and for different velocity. 


\section{Dispersion of the vapor}

The dry air projected at the exit of the nozzle interacts with the vapor above the evaporation surface. The flow of air drives the latter and dispersed in the surrounding space. In figures 12 and 13 shows according to Reynold's number, the competition between the airflow and the natural convection in the evaporation zone. At low number $\mathrm{Re}$, the natural convection which is a vertical movement is preponderant relative to the airflow. The movement of air is slowed down, which reduces the entrainment of steam near the wall and consequently the dispersion. When Re believes, the flow velocity is higher (see Figure 13), steam entrainment, and dispersion increase.

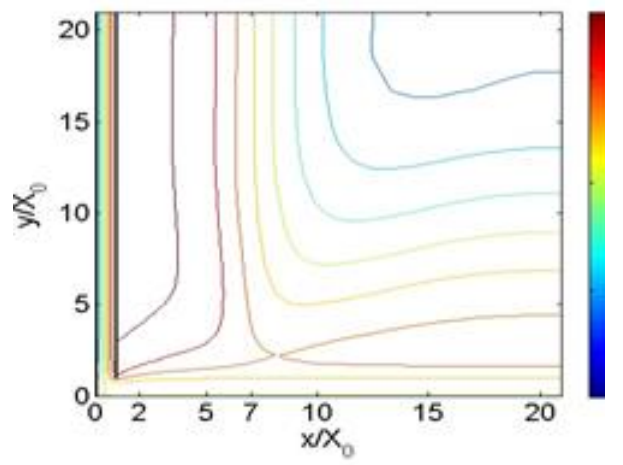

Fig. 12. Streamlines in the entire domain, at low number Reynolds.

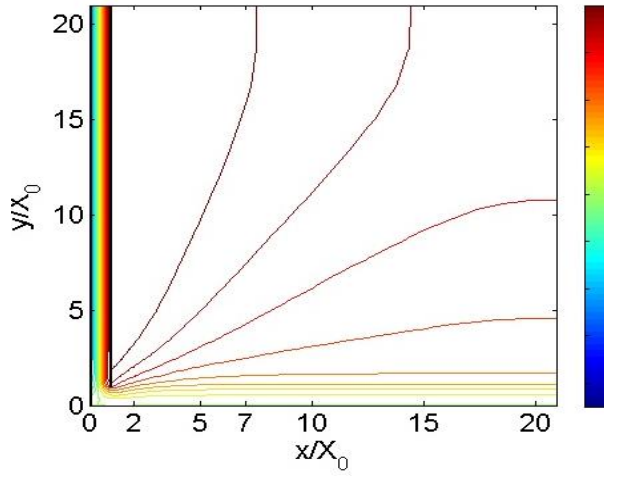

Fig. 13. Streamlines in the entire domain, when the flow velocity is higher.

In order to more clearly see the evolution of the mass fraction field as a function of the Reynolds number, the mass iso-fraction fractions of the vapor in the zone in the vicinity of the wall are enlarged in figure $14-a, b, c, d$ et e. Where the maximum mass fraction defined by $\omega_{v-\max }$ moreover, determined throughout the calculation domain, indicates the importance of the dispersion of the vapor when it is lower. 

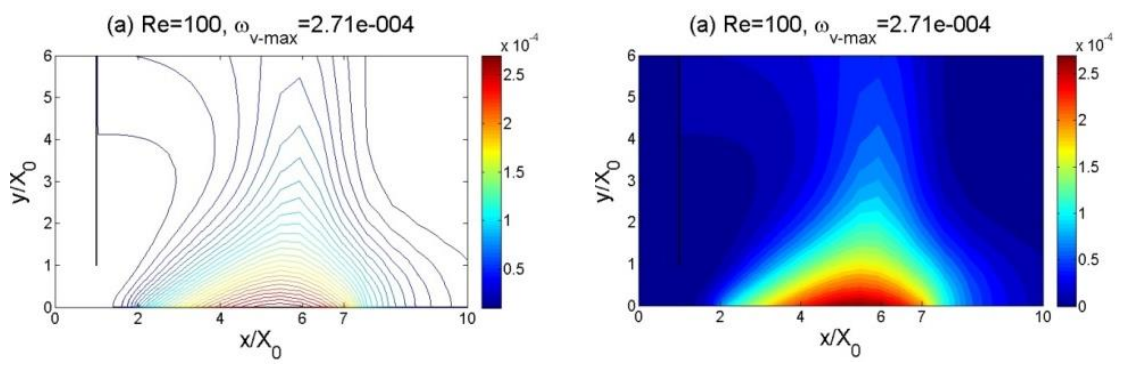

(a)
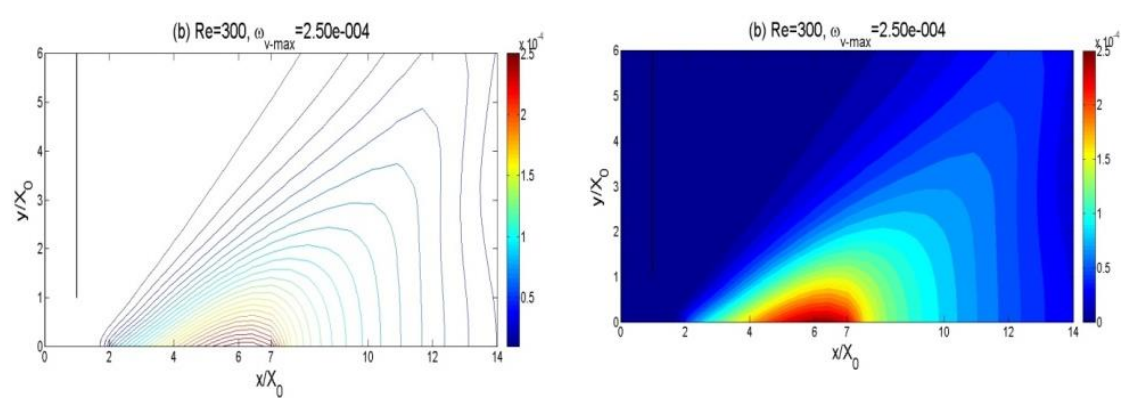

(b)
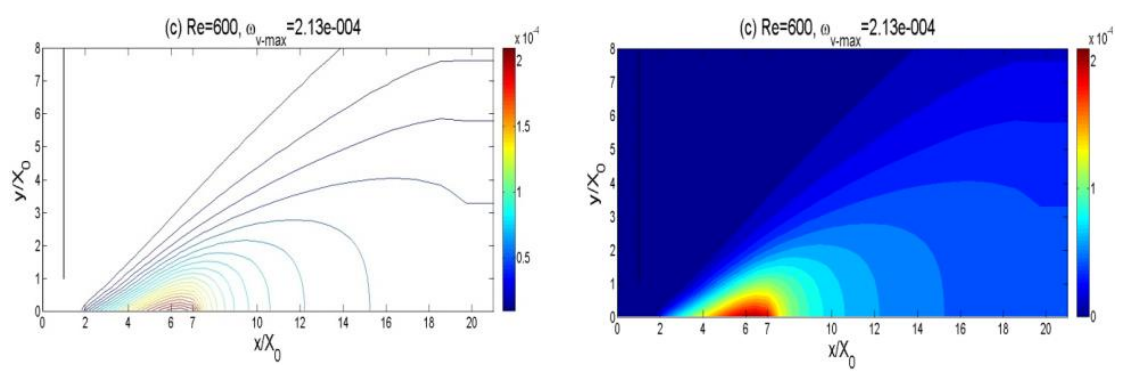

(c)
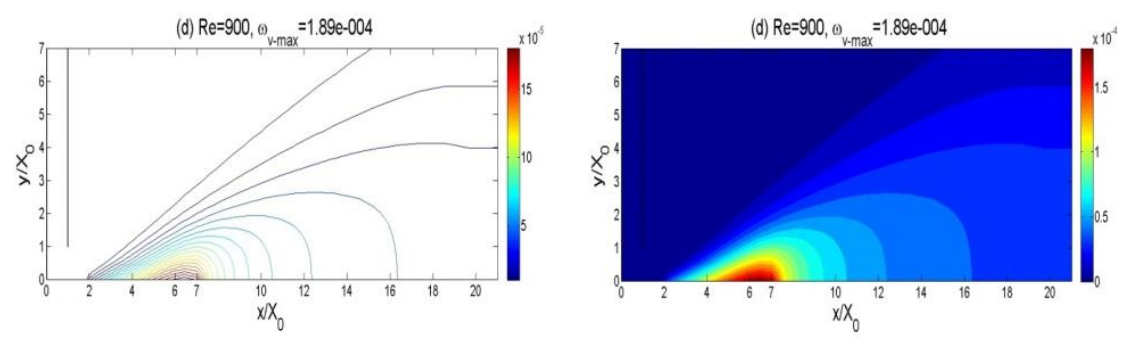

(d) 

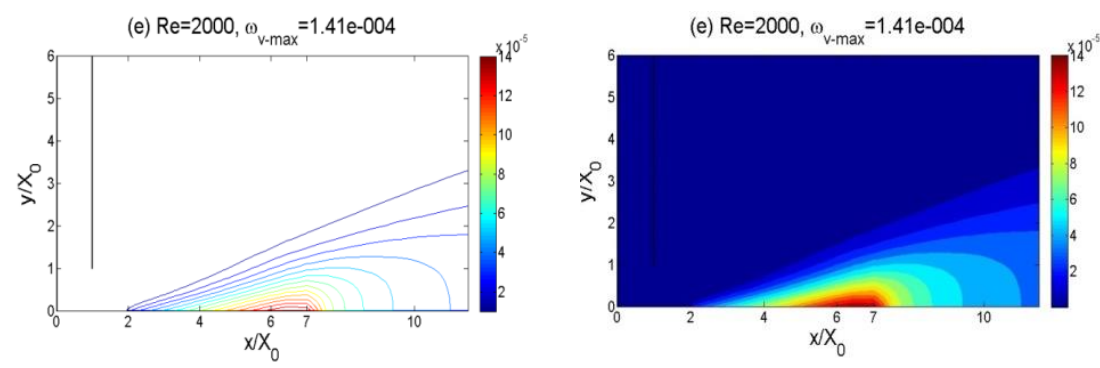

(e)

Fig. 14-a, $b, c, d, e$. Lines of mass iso-fractions in a part of the computation domain for different Reynolds numbers (from 100 to 2000).

\section{Transient regime}

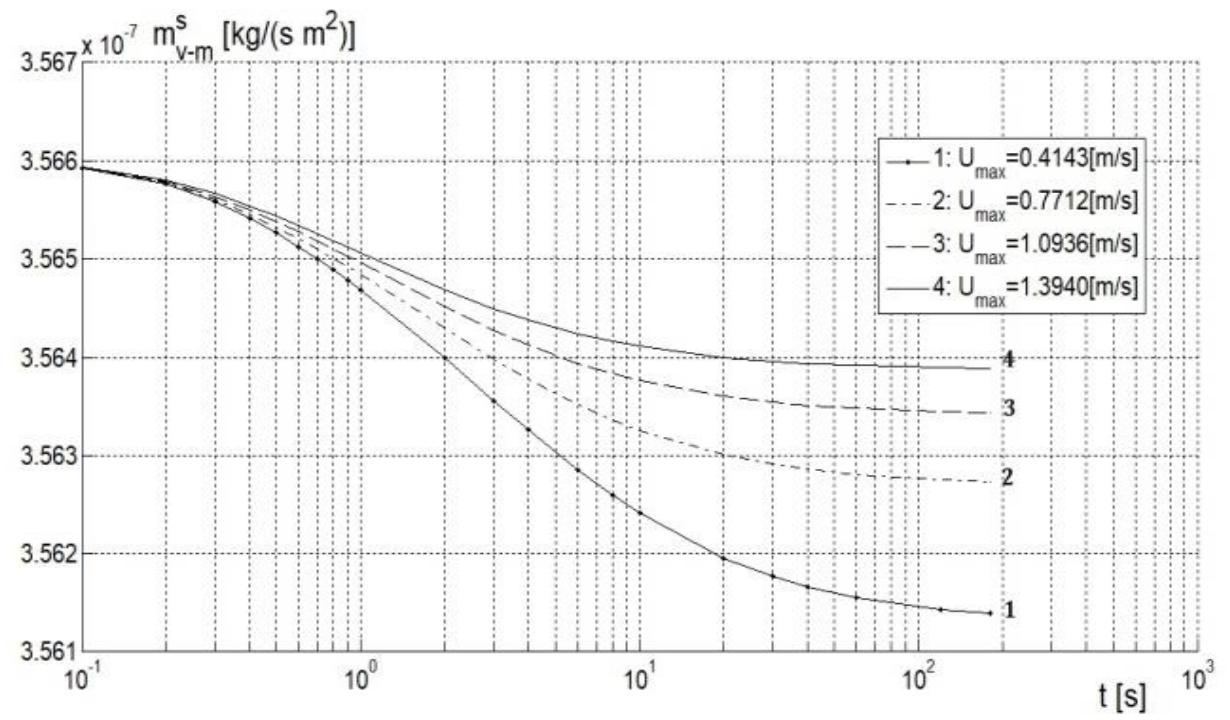

Fig. 15. Average mass flow rates $m_{v-m}^{s}$ as a function of time t and for different velocities $U_{\max }$.

In figure 15, the curves 1-4 show the temporal evolution of the mass flow rate of vapor according to the different velocity of the airflow. The flow rate is maximal at the initial moment then decreases in time to tend towards a constant value. As a result, the evaporation flow has two regimes, one transient, and the second stationery. The flow rate admits the same maximum value, for the different velocities of the airflow. The duration of the transient regime decreases as the flow velocity increases. In steady-state, the value of the flow approaches the maximum value when the velocity increases. 


\section{Conclusions}

A method of modeling evaporation through a porous and permeable flat wall surface has been proposed. In the presence of a laminar flow of dry air, this method is based on the model of the stagnant film. The numerical resolution of the coupled equations of the dynamic field, temperature, and mass fraction of the vapor allowed us to determine the evaporation rate. The study of the influences of the various parameters shows the preponderance of the temperature followed by the airflow velocity and the pressure on the evaporation rate. The analysis of the temporal evolution of the mass flow rate of the steam shows that when the velocity increases the duration of the transient regime decreases. While in steady-state the rate of evaporation approaches the maximum value.

\section{Nomenclature}

Latin symbols

$\mathrm{C}_{\mathrm{p}}=$ specific heat at constant pressure $[\mathrm{J} /(\mathrm{kg} \mathrm{K})]$

$\mathrm{C}_{\mathrm{p} 0}=$ specific heat at constant pressure at the inlet of the nozzle $[\mathrm{J} /(\mathrm{kg} \mathrm{K})]$

$\mathrm{D}_{\mathrm{v}-\mathrm{a}}=$ diffusion coefficient of the vapor in the air $\left[\mathrm{m}^{2} / \mathrm{s}\right]$

$\mathrm{D}_{\mathrm{v}-\mathrm{a}_{0}}=$ diffusion coefficient of the vapor in the air at the inlet of the nozzle $\left[\mathrm{m}^{2} / \mathrm{s}\right]$

$\mathrm{g}=9.80655\left[\mathrm{~m} / \mathrm{s}^{2}\right]$, universal acceleration

$\mathrm{H}=$ distance nozzle-impact surface $[\mathrm{m}]$

$\mathrm{L}=$ permeable surface length $[\mathrm{m}]$

$\mathrm{j}_{\mathrm{v}, \mathrm{s}}=$ mass flow rate of water vapor diffusion $[\mathrm{kg} / \mathrm{s}]$

$\mathrm{k}=$ thermal conductivity of the fluid $[\mathrm{W} /(\mathrm{m} \mathrm{K})]$

$\mathrm{k}_{0}=$ thermal conductivity of the fluid at the inlet of the nozzle [W/(m K)]

$\dot{\mathrm{m}}_{\mathrm{v}}^{\mathrm{s}}=$ surface evaporation rate $[\mathrm{kg} / \mathrm{s}]$

$\mathrm{M}_{\mathrm{a}}=$ molar mass of air $[\mathrm{g} / \mathrm{mol}]$

$\mathrm{M}_{\mathrm{v}}=$ molar mass of water vapor $\mathrm{g} / \mathrm{mol}$

$\dot{\mathrm{m}}_{\mathrm{v}}^{\mathrm{s}}=$ surface evaporation rate $[\mathrm{kg} / \mathrm{s}]$

$\dot{\mathrm{m}}_{\mathrm{v}}=$ local evaporation rate $[\mathrm{kg} / \mathrm{s}]$

$\mathrm{P}_{0}=$ total thermodynamic pressure $[\mathrm{Pa}$ ou atm $]$

$\mathrm{p}=$ fluid pressure $[\mathrm{Pa}]$

$\mathrm{p}_{\mathrm{v}}=$ partial pressure of water vapor $[\mathrm{Pa}]$

$\mathrm{q}_{\mathrm{s}}=$ local heat flux on the porous surface $\left[\mathrm{W} / \mathrm{m}^{2}\right]$

$\mathrm{R}=$ perfect gas constant

$\mathrm{t}=$ time $[\mathrm{s}]$

$\mathrm{T}_{\mathrm{a}}=293.15[\mathrm{~K}]$ ambient temperature

$\mathrm{T}_{0}=$ temperature of the air at the inlet of the nozzle $[\mathrm{K}]$

$\mathrm{T}_{\mathrm{a}}=293.15[\mathrm{~K}]$ ambient temperature

$\mathrm{T}_{0}=\mathrm{T}_{\mathrm{a}}$ air temperature at the nozzle inlet $[\mathrm{K}]$

$\mathrm{T}_{\mathrm{g}}=$ gas temperature $[\mathrm{K}]$

Greek symbols

$\delta_{\mathrm{c}}=$ stagnant film thickness [m]

$\mu=$ dynamic viscosity of the fluid $[\mathrm{kg} /(\mathrm{m} \mathrm{s})]$

$\mu_{0}=$ dynamic viscosity of the fluid at the inlet of the nozzle $[\mathrm{kg} /(\mathrm{ms})]$

$\mathrm{p}=$ density mass of the fluid $\left[\mathrm{kg} / \mathrm{m}^{3}\right]$ 
$\rho_{0}=$ density mass of the air at the inlet of the nozzle $\left[\mathrm{kg} / \mathrm{m}^{3}\right]$

$\rho_{\mathrm{a}}=$ density mass of the air $\left[\mathrm{kg} / \mathrm{m}^{3}\right]$

$\rho_{\mathrm{v}}=$ density mass of water vapor $\left[\mathrm{kg} / \mathrm{m}^{3}\right]$

$\omega_{\mathrm{v}}=$ mass fraction of water vapor

Indices

$0=$ on the entry of the nozzle

$=$ dimensionless value

\section{Number of dimensionless group}

$\mathrm{Fr}=\mathrm{V}_{\max 0}^{2} /\left(\mathrm{gX}_{0}\right)$ number of Froude

$\operatorname{Pr}=\left(\mathrm{C}_{\mathrm{p} 0} \mu_{0}\right) / \lambda_{0}$ number of Prandtl

$\operatorname{Re}=\left(\rho_{0} \mathrm{X}_{0} \mathrm{~V}_{\max 0}\right) / \mu_{0}$ number of Reynolds

$S_{c}=\mu /\left(\rho X_{0}\right)$ number of Schmidt

\section{References}

[1] P. W. M. Brighton: J Fluid Mech, 159 (1985) 323-345.

[2] P. I. Kawamura, Donald Mackay: J Hazard Mater, 15 (1987) 343-364.

[3] K. Braun, K. Caplan, Evaporation rate of volatile liquids. Washington: US environmental protection Agency. (1989)

[4] H. John, Lienhard IV, John H. Lienhard V, A Heat Transfer Textbook Fourth Edition by Press Cambridge Massachusetts Version 2.11 dated 17 July 2017.

[5] H.K. Versteeg and W.Malalasekera, An introduction to computational fluid dynamics. The finite volume method. C Longman Group Ltd 1995.

[6] E. N. Fuller, Paul D. Schettler, J. Calvin Giddings: Ind Eng Chem, 58 (1966) 18-27.

[7] T. F. Irvine, P. Liley, Steam and gas tables with computer equations. San Diego: Academic Press; 1984.

[8] Y. S. Touloukian, R. W. Powell, C. Y. Ho, P. G. Clemend, Thermo physical properties of matter, vol. 1. NY; 1970.

[9] P. T. Tsilingiris: Energy Convers and Manage, 49 (2008) 1098-1110.

[10] [10] George SK Wong, Tony FW Embleton: The Journal of the Acoustical Society of America 76 (1984) 555-559.

[11] R. C. Reid, J. M. Prausnitz, B. E. Poling, The properties of gases and liquids, Chemical Engineering Series. McGraw Hill Int. Editions; 1988.

[12] E. N. Fuller, P. D. Schettler, and J. C. Giddings, Ind. Eng. Chem. 58(5), 19 (1966).

[13] S. V. Patankar, Numerical heat transfer and fluid flow. Mc Graw -Hill, New York (1980).

[14] J. F. Sacadura. Initiation aux transferts thermiques. Technique et Documentation Paris. 1980 I.S.B.N. 2-85206-618-1

[15] F. Kreith, R. F. Boehm, et. al. "Heat and Mass Transfer" Mechanical Engineering Handbook Ed. Frank Kreith Boca Raton: CRC Press LLC, 1999.

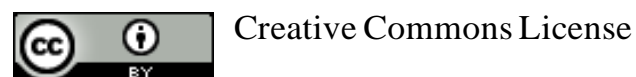

This work is licensed under a Creative Commons Attribution 4.0 International License. 